\title{
A novel antioxidant and antimicrobial compound produced by Bacillus firmicutes.
}

\author{
Youssri M Ahmed ${ }^{1,2,3 *}$, Ibtihaj J Jambi ${ }^{1}$ \\ ${ }^{1}$ Department of Biochemistry, Faculty of Science, King Abdulaziz University, Jeddah, Saudi Arabia \\ ${ }^{2}$ Production of Bioproducts for Industrial Applications Research Group and Experimental Biochemistry Unit, King \\ Fahd Medical Research Center, King Abdulaziz University, Kingdom of Saudi Arabia
}

${ }^{3}$ Department of Microbial Biotechnology, Genetic Engineering and Biotechnology Research Division, National Research Center, Dokki, Cairo, Egypt

\begin{abstract}
In this study, antioxidant and antimicrobial compounds were produced from a dates seeds powder containing medium by $B$. firmicutes, a bacterial strain isolated from Al-Ain Alhara hot springs located in Gazan area in Saudi Arabia. The Total Antioxidant Capacity (TAC) of culture supernatant of $B$. firmicutes by the phosphomolybdenum was $2.5 \mathrm{mg} / \mathrm{ml}$ of culture medium, the total phenolic compounds is $5.3 \mathrm{mg} / \mathrm{ml}$ of culture medium and radical scavenging activity was done by DPPH. The greatest scavenging rate of antioxidants was $60 \%$. In addition, its antibacterial activity was performed after treatment the culture medium with methanol or ethyl acetate. As antimicrobial ethyl acetate, extract is more effective than methanol. In both ethyl acetate and methanol extract the highest antibacterial activity was observed against $E$. faecalis with a maximum diameter inhibition zone of $25 \mathrm{~mm}, 15 \mathrm{~mm}$ respectively while, the lowest activity was detected against $P$. aeruginosa with inhibition diameter zone $14 \mathrm{~mm}$ and $10 \mathrm{~mm}$ respectively. Analysis by Thin Layer Chromatography (TLC) for ethyl acetate and methanol extracts revealed the presence one spot in the front in ethyl acetate while the spot of methanol come latter and maybe have another spot. The molecular mass of ethyl acetate extract was $304.53 \mathrm{~m} / \mathrm{z}$ and methanol extract was $701.57 \mathrm{~m} / \mathrm{z}$ as determined by MS.
\end{abstract}

Keywords: Antibacterial, Antioxidant, Bacillus firmicutes, Dates seed.

Accepted on April 16, 2018

\section{Introduction}

The date seeds considered a waste product of many date processing plants producing pitted dates, date syrup and date confectionery. At present, seeds are used mainly for animal feeds in the cattle, sheep, and camel and poultry industries. Although, these date seed contain about $82 \%$ carbohydrates as reported by Besbes et al. [1] a little attention has been paid to investigate microbial conversion of date seeds to produce bioactive compounds such as antibiotics, mycotoxins, alkaloids, food grade pigments, plant growth factors, and antioxidant compounds [2]. Abou-Zeid et al. [3] was used date seed lipid and hydrolysate for production tetracycline.

Nowadays, to confront the growing antimicrobial resistances, modern medicine Focus on natural products for novel antibiotics and antimicrobials. The multifarious antimicrobial compounds produced by various Bacillus strains have the ability to address the multidrug resistance problems. Bacillus isolates are rather well known for the production of a vast array of structurally unrelated antimicrobial compounds, which include lipopeptides such as iturin, surfactin, fengycins, bacteriocins, and bacteriocin such as inhibitory substances (BLIS) [4]. Moreover, these species produce other bioactive molecules such as catecholic siderophore bacillibactin [5]. Sequestration can reduce the occurrence of free radicals [6]. Free radicals or reactive oxygen species are known to cause oxidative damage to biological macromolecules, leading to a number of disorders including cancer, atherosclerosis, cardiovascular diseases, aging and inflammatory diseases [7]. Synthetic antioxidants that have been extensively used in industrial processing are being investigated for their toxic and carcinogenic effects $[6,8]$. Recently, the interest in finding natural antioxidant agents with low cytotoxicity has increased significantly [8]. Several studies have focused on plant compounds $[9,10]$. However, only a few reports have been conducted on the antioxidant power of microbial extracts [6]. Kumar et al. [11] reported that several bacteria were found to produce antioxidant compound as Bacillus simplex, Bacillus natto, Bacillus cereus, Lactobacillus dextranicum, Micrococcus freudenreichii and Sarcina lutea. Besides bacteria, some fungi, few Actinomycetes and yeasts were also found to produce the compounds with antioxidant activity. Dey 
et al. [12] extracted antioxidant phenolic compounds from Rhizopus oryzae fungi cultured on wheat solid medium. Matsuo [13] observed that the oxidation of vegetable oil was inhibited by an addition of soybean-curd refuse fermented with A. oryzae or Rhizopus oligosporus. Lertcanawanichakul et al. [14] extracted A2 antioxidant and antimicrobial compounds from Streptomyces lydicus. Streptomyces spp. SRDP-H03 and BI244 exhibited antioxidant activity [15].

The present study addressed partial characterization of new antioxidant compound along with an evaluation of its antibacterial produced from $B$. firmicutes.

\section{Materials and Methods}

\section{Materials}

Maddina aqgwa dates pits powder was obtained from local market in Maddina. Other chemicals used were obtained in analytical grade. Microorganism was isolated from two thermal hot springs located in Gazan area in Saudi Arabia.

\section{Media}

Mineral dates seed powder medium (MDPM) (g/l): $\mathrm{NH}_{4} \mathrm{Cl}$, $1 ; \mathrm{K}_{2} \mathrm{HPO}_{4}, 0.5 ; \mathrm{KH}_{2} \mathrm{PO}_{4}, 1 ; \mathrm{MgSO}_{4} .7 \mathrm{H}_{2} \mathrm{O}, 0.2 ;$ Dates seed powder, 5. $\mathrm{pH}$ was adjusted to $\mathrm{pH} 7.0-20 \mathrm{~g} / \mathrm{L}$ agar was added in solid medium (MDPMA).

Maintenance medium (g/l): Meat extract, 10, peptone, 10; $\mathrm{NaCl}, 5$, dates seed powder 10, agar, 20. $\mathrm{pH}$ adjusted at 7 . The slants were inoculated with bacterial strain and incubated at $37^{\circ} \mathrm{C}$ for $24 \mathrm{~h}$. The slants were maintained at $0-4^{\circ} \mathrm{C}$ in refrigerators.

\section{Inoculum medium (g/l): Bacillus}

Basal medium: Unless stated otherwise the bacterium will be grown in shake flasks in a basal medium of the following composition: (g/l) $2.5 \quad \mathrm{KH}_{2} \mathrm{PO}_{4} ; 2.5 \quad \mathrm{Na}_{2} \mathrm{HPO}_{4} ; 1 \quad \mathrm{NaCl} ; 2$ $\mathrm{NaNO}_{3} ; 2$ yeast extract; $0.05 \mathrm{MgSO}_{4} .7 \mathrm{H}_{2} \mathrm{O}$ and $0.075 \mathrm{CaCl}_{2}$. The basal medium will be supplemented with $10 \mathrm{~g}$ dates seed powder. The $\mathrm{pH}$ of the medium will be adjusted to $\mathrm{pH} 7.0$. The basal medium was sterilized by autoclaving at $121^{\circ} \mathrm{C}$ for 15 min. Erlenmeyer flasks $(250 \mathrm{ml})$ containing $50 \mathrm{ml}$ of basal medium were inoculated at $10 \%(\mathrm{v} / \mathrm{v})$ level and incubated at $37^{\circ} \mathrm{C}$ on a rotary shaker $(150 \mathrm{rpm})$ for $48 \mathrm{~h}$. Samples were removed at intervals for the determination of growth of cells and antioxidant concentration.

Inoculum medium nutrient broth medium: Peptone-5 g/L meat extract-1 g/L yeast extract- $2 \mathrm{~g} / \mathrm{L}$ sodium chloride- $5 \mathrm{~g} / \mathrm{L}$, $\mathrm{pH}-7.0 \pm 0.2$ nutrient agar for maintenance bacteria, the same nutrient broth in addition to $20 \mathrm{~g} / \mathrm{L}$ agar.

Müller-Hinton agar: It is typically contains: $2.0 \mathrm{~g} / \mathrm{L}$ beef extract, $17.5 \mathrm{~g} / \mathrm{L}$ casein hydrolysate, $1.5 \mathrm{~g} / \mathrm{L}$ starch, $17.0 \mathrm{~g} /$ $\mathrm{L}$ agar dissolved in 1 litre of distilled water. $\mathrm{pH}$ was adjusted to neutral at $25^{\circ} \mathrm{C}$ [16]. Müller-Hinton broth the same medium without agar.

\section{Microorganisms}

The tested microorganisms included the following:

Gram-positive bacteria; Enterococcus faecalisis ATTC (292121); Staphylococcus aureus ATTC (29213); Gramnegative bacteria; Escherichia coli ATCC (25922); Klebsiella pneumoniae ATTC (70060); Proteus mirabilis ATTC (14153);

Pseudomonas aeruginosa (27853); These strains were obtained from King Abdul-Aziz University Hospital.

\section{Methods}

\section{Isolation of Bacillus firmicutes}

Water samples were collected from two thermal hot springs located in Gazan area in Saudi Arabia, these are Al-Ain Alhara (or Al-Khawaba) located at a distance of about $50 \mathrm{~km}$ southeast of Gazan city.

Samples were collected in $500 \mathrm{ml}$ sterile thermal glass containers, which keep the temperature of the water samples constant. $5 \mathrm{ml}$ from each water sample was inoculated to 500 $\mathrm{ml}$ Erlenmeyer flash containing $50 \mathrm{ml}$ (MDPM) medium.

The inoculated flasks will be incubated at $37^{\circ} \mathrm{C}$ with shaking at $180 \mathrm{rpm}$ for $48 \mathrm{~h}$ millilitre of cultured flask were striking on petri dish containing (MDPMA) media, then incubated at $37^{\circ} \mathrm{C}$ in a bench top incubator for 24 to $48 \mathrm{~h}$. For the purpose of getting pure culture, distinctive colonies were picked up and transferred to a fresh (MDPMA)agar plates, then incubated at $37^{\circ} \mathrm{C}$ in a bench top incubator for 24 and $48 \mathrm{~h}$ till pure culture were obtaining.

\section{Microbial methods}

Phylogenetic analysis: Analysis of genes sequences of bacteria was done by phylogenetic method using reference sequences homology from the NCBI database using MEGA 4 programme (Tamura et al.). Phylogenetic trees were constructed by distance matrix-based cluster algorithms viz. un-weighted pair group method with averages un-weighted pair group method using arithmetic averages (UPGMA), neighbour-joining, maximum likelihood, and maximumparsimony analysis as described elsewhere [17]. The trees were rooted using Escherichia coli strain K 12 MG1655 (accession no. U00096) as out-group; the stability of trees obtained from above cluster analysis was assessed by using BOOTSTRAP program in sets of 1000 re-samplings (MEGA 4) [18].

Antimicrobial activity: For the experiments, a loopful of the bacterial working stocks were enriched on a tube containing 9 $\mathrm{ml}$ of Nutrient broth then incubated at $37^{\circ} \mathrm{C}$ for $24 \mathrm{~h}$.

Antimicrobial activity was done according to the protocol described by Hajlaoui et al. [19]. Agar diffusion well-variant: according to Smânia et al. [20].

The bacterial inoculum was uniformly spread using sterile cotton swab on a sterile petri dish contain Müller-Hinton agar. $40 \mu \mathrm{L}$ of each the supernatant extract (Methanol-ethyl acetate) were added to each of the wells $(7 \mathrm{~mm}$ diameter holes cut in 
the agar gel). The systems were incubated for $24 \mathrm{~h}$ at $37^{\circ} \mathrm{C} \pm$ $1^{\circ} \mathrm{C}$, under aerobic conditions. After incubation, confluent bacterial growth was observed. Inhibition of the bacterial growth was measured in $\mathrm{mm}$. Tests were performed in duplicate.

Determination of minimum inhibitory concentration (MIC): The MIC for different strains was determined by using a microtiter plate dilution method in appropriate broth using 96-well plates according to the Clinical and Laboratory Standard Institute (CLSI) guidelines [21]. Using 0.5 McFarland standards, $\mathrm{CFU} / \mathrm{mL}$ of each indicator bacteria was prepared and subjected to varying concentration of the methanol and ethyl acetate $0.4-100.0 \mu \mathrm{g} / \mathrm{mL}$. The microtiter plates were incubated at incubator under shaking condition. The lowest concentration that inhibited growth of indicator strains was recorded.

\section{Chemicals analyses of the extract}

Preparation of the methanol and ethyl acetate extracts: $B$. firmicutes were cultured for $48 \mathrm{~h}$ then centrifuged and $200 \mathrm{ml}$ of the supernatant were concentrated to $20 \mathrm{ml}$. Then $10 \mathrm{ml}$ was treated with methanol and another $10 \mathrm{ml}$ was treated with ethyl acetate. Both fractions were concentrated to $2 \mathrm{ml}$ then it used for antibacterial and TLC analyses.

Determination of moisture: The method reported the A.O.A.C [22] for moisture determination. Sample (5 g) was weighed in watch glass the sample was dried at $120 \pm 2^{\circ} \mathrm{C}$ to constant weight.

Determination of ash: The method reported in the A.O.A.C [22] was applied. Sample ( $2 \mathrm{~g}$ ) was weighed into porcelain crucible and in muffle furnace at $550{ }^{\circ} \mathrm{C}$ until constant weight.

\section{Antioxidant assays}

Test for phenolics [23]: Neutral ferric chloride was added to each fraction. Appearance of bluish green colour indicated presence of phenolics.

Test for flavonoids: Dilute ammonia $(5 \mathrm{ml})$ was added to a portion of sample solution in water. Concentrated sulphuric acid $(1 \mathrm{ml})$ was added. A yellow colouration that disappear standing indicated the presence of flavonoids.

Condensed tannins: Condensed tannins were estimated using the method of Sun et al. [24] with some modifications.

Total antioxidant capacity (TAC): Phosphomolybdenum assay. The total antioxidant capacity (TAC) of culture filtrate was spectrophotometrically determined by the phosphomolybdenum assay using the method described by Prieto et al. [25]. The antioxidant capacity of each sample was expressed as Ascorbic Acid (AA) equivalent using the following linear equation established using ascorbic acid (Figure 1) as standard: $\left(\mathrm{A}=0.0037 \mathrm{C}+0.0343 ; \mathrm{R}^{2}=0.991\right)$ where $\mathrm{A}$ is the absorbance at $695 \mathrm{~nm}$ and $\mathrm{C}$ the concentration as ascorbic acid equivalent $(\mu \mathrm{g} / \mathrm{ml})$ [26]. The values are presented as the means of triplicate analysis.

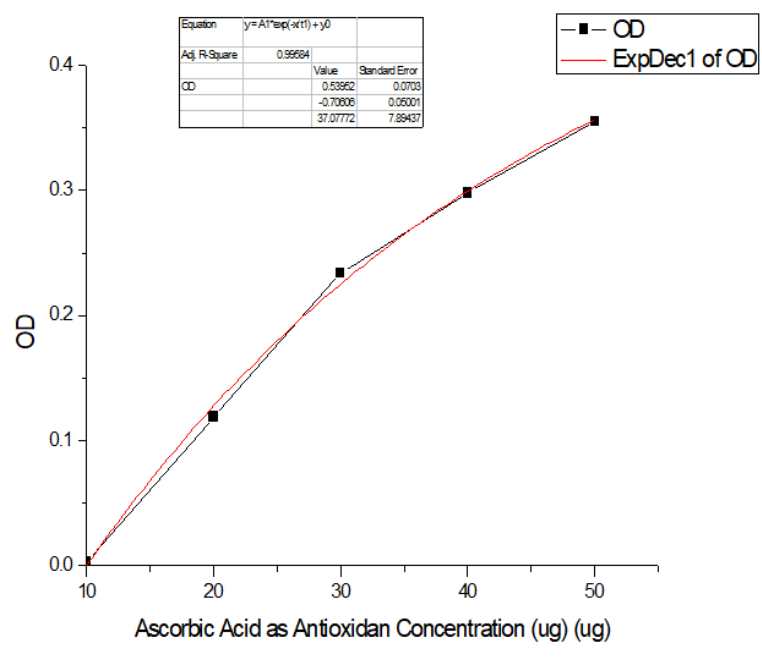

Figure 1. Stander curve for total antioxidant capacity.

DPPH scavenging activity assay: DPPH radical scavenging activity was measured using the method described with slight modifications [27].

$1 \mathrm{~mL}$ of sample was added to $2 \mathrm{~mL}$ of DPPH $(0.15 \mathrm{mM}) .1 \mathrm{~mL}$ of $100 \%$ methanol was added to $2 \mathrm{~mL}$ of DPPH as blank control. The mixture was allowed to stand for $30 \mathrm{~min}$ in the dark at room temperature. After $30 \mathrm{~min}$, absorbance was measured at $517 \mathrm{~nm}$. All samples were tested in triplicate. The results were expressed in percentage of radical scavenging activity, calculated using the following formula:

$\%$ radical scavenging activity $=($ A Blank-A Sample $) \times 100 \%$

A Blank: A Blank refers to the absorbance of the blank control whereas A Sample is the absorbance of the tested samples.

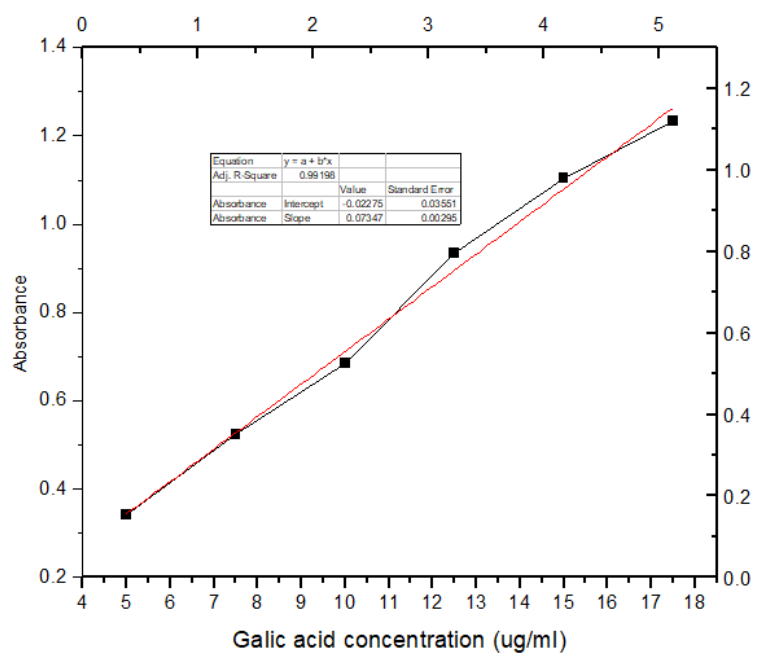

Figure 2. Calibration curve of standard Gallic acid for determination of total phenolics.

Total phenolic content analysis: Total phenolic content of the supernatant extract of B. firmicutes was determined with FolinCiocalteu reagent according to the method [28] with slight modification, using Gallic Acid as a standard. A $0.1 \mathrm{~mL}$ of extract was placed into a $10 \mathrm{~mL}$ measuring flask and $0.5 \mathrm{~mL}$ of 
Folin-Ciocalteau reagent was added to the extract. The measuring flask was allowed to stand at room temperature for $5 \mathrm{~min}$. Then, $1.5 \mathrm{~mL}$ of $20 \%(\mathrm{w} / \mathrm{v}) \mathrm{Na}_{2} \mathrm{CO}_{3}$ was added to the mixture. The mixture was adjusted until the volume reaches 10 $\mathrm{mL}$ with distilled water. After $30 \mathrm{~min}$ at room temperature, absorbance was measured at $765 \mathrm{~nm}$ versus a blank by using a spectrophotometer (Shimadzu UV 1800, Japan). Total phenol value was expressed as $\mathrm{mg}$ Gallic Acid 9 (Figure 2) Equivalent/g.

\section{Chromatographic analysis}

Thin layer chromatography (TLC): (A) Identification of antioxidant for different cultured time. TLC was used to assess the purity and number of compounds in the supernatant extract of $B$. firmicutes for different days (1-7 d) was analyzed on precoated $5 \times 10 \mathrm{~cm}, 0.25 \mathrm{~mm}$ thickness silica gel 60 F254 aluminium plates; (B) Both methanol and ethyl acetate were analyzed on pre-coated $5 \times 10 \mathrm{~cm}, 0.25 \mathrm{~mm}$ thickness silica gel 60 F254 aluminium plates.

1. The extracts were spotted on TLC plate by using a fine glass capillary tube.

2. The mobile: Chloroform: Methanol (10:1).

3. The developed TLC was visualized under UV lamp.

Identification by using MS/MS: MS experiments were carried out using a Thermo LCmsms, model LTQ XL Instrument and with an accelerating voltage of $16 \mathrm{kV}$. Hypersil GOLD $^{\mathrm{TM}} \mathrm{C} 18$ selectivity LC columns.

\section{Results and Discussion}

Date products such as syrup, jam, vinegar and sweets are all important and used by local consumers. Date seeds considered a waste product of many date processing plants producing pitted dates, date syrup and date confectionery. At present, seeds are used mainly for animal feeds in the cattle, sheep and camel and poultry industries. With world production of dates reaching 6.9 million tons in 2004, from this approximately 863 thousand tons of date seeds are produced [29].

\section{Dates seed ago (pits) chemical composition}

Results for chemical composition of date ago seed pits are shown in Table 1. The ash, moisture, protein, fat, and fiber contents (dry weight basis) were 0.9, 4.8, 5.47, 6.1, 9.0 and $22 \%$, respectively. Accordingly, total carbohydrate content was $57.2 \%$. Our results fall within the range of date pits values previously reported by Attalla et al. [30], Hamada et al. [31] and Al-Farsi et al [32] who researched the functional properties of date seeds, their reported composition was 3.1-7.1\% moisture, 2.3-6.4\% protein, 5.0-13.2 fat, 0.9-1.8\% ash and $22.5-80.2 \%$ dietary fiber.

Table 1. Chemical composition of date pits/100 g powder.

\begin{tabular}{ll}
\hline Ingredients & $\mathrm{DP} / 100 \mathrm{~g}$ \\
\hline Ash $(\mathrm{g})$ & 0.9 \\
\hline
\end{tabular}

\begin{tabular}{ll}
\hline Moisture $(\mathrm{g})$ & 4.8 \\
\hline Protein $(\mathrm{g})$ & 6.1 \\
\hline Total fat $(\mathrm{g})$ & 9 \\
\hline Fiber (g) & 22 \\
\hline Carbohydrates $(\mathrm{g})$ & 57.2 \\
\hline
\end{tabular}

\section{Identification of Bacillus strain}

Molecular characterization of these strains was done by DNA isolation (CTAB method) and $16 \mathrm{~S}$ rDNA analysis. Further these amplified 16S rDNA sequences of the bacterial strains was blasted using online tool (MEGA 4). The taxonomical identification was done by the phylogenetic tree construction and the comparison of this bacterial strain sequences with other homologous bacterial sequences.

The strain was gram positive, aerobic, spore forming short rod Bacillus. The organism was able to grow between $30-60^{\circ} \mathrm{C}$ and Several biochemical tests as Catalase reaction positive, oxidase reaction positive, nitrate oxidase positive, gram staining and $3 \% \mathrm{KOH}$ negative, idols negative and maltose negative in addition to phylogenetic tree based on different species of Bacillus was constructed using neighbour joining method (Figure 3), indicated that strain was very closely related with Bacillus firmicutes strain. Therefore it was named B. firmicutes strain.

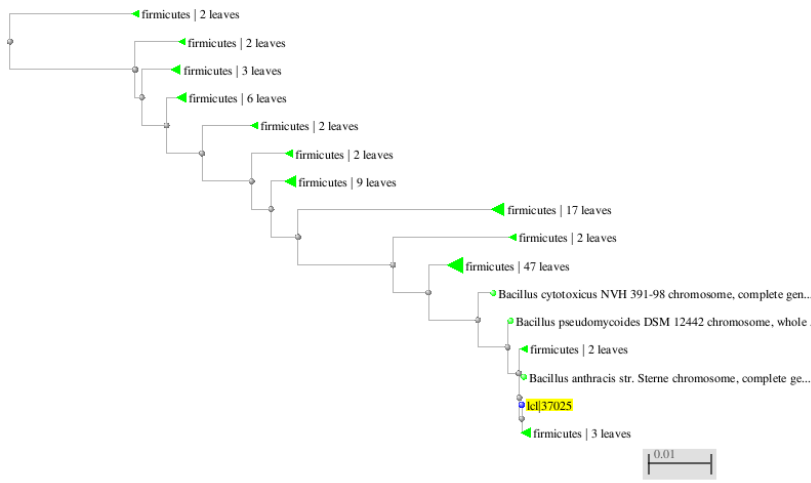

Figure 3. Identification of Bacillus by using phylogenetic tree method indicated that strain was very closely related with Bacillus firmicutes strain.

\section{Phytochemical investigation}

The present study carried out on the supernatant of the culture medium after incubation for $2 \mathrm{~d}$ revealed the presence of medicinally active constituents (Table 2). It was observed from the preliminary phytochemical investigation that phenolics, flavonoids and tannin were present in the supernatant. Deschamps et al. [33] reported that bacterial strains identified as Klebsiella pneumonia and Corynebacterium sp. were produced Gallic acid.

Table 2. Phytochemical constituents of culture ago pits medium.

Test Supernatant




\begin{tabular}{lc}
\hline Tannins & + \\
\hline Sugars & + \\
\hline Phenolic & + \\
\hline Flavonoids & + \\
\hline
\end{tabular}

\section{Total antioxidant capacity (TAC)}

The total antioxidant capacity (TAC) of culture supernatant of $B$. firmicutes was determined by the phosphomolybdenum assay using the method described by Prieto et al. [25]. As shown in Figure 1 that the total (TAC) compounds in the culture supernatant is $2.5 \mathrm{mg} / \mathrm{ml}$ of culture medium. The same results were detected by Janardhan et al. [34] who detected potent total antioxidant activity produced by isolated actinomycetes.

\section{Determination of total phenolic compounds}

Phenolic compounds were responsible for the antioxidant activity and many biological activities such as antibacterial, anticancer, anti-allergic, anti-diabetes, anti-aging, antiinflammatory and anti-HIV activities the most important classes of natural products [35]. The produced total phenolic compounds the culture supernatant of the isolated, selected $B$. firmicutes were determined and expressed as Gallic acid equivalent. The highest amount of phenolic compounds is 5.3 $\mathrm{mg} / \mathrm{ml}$ of culture medium as shown in Figure 2. The same results were reported by Tebbal et al. [36] who found phenolic compounds in the isolated cyanobacteria. Martins et al. [37] have reported that the use of methanol for extraction of the total phenolic content has manifested a higher amount yield in Oscillatoria agardhii and Anabaena sphaerica.

\section{DPPH radical scavenging activity}

Free radical scavenging is one of the known mechanisms by which antioxidants inhibit cellular damage. DPPH is one of the compounds that have a proton free radical with a characteristic absorption, which decreases significantly on exposure to proton radical scavengers. Furthermore, it is well accepted that the DPPH free radical scavenging by antioxidants is due to their hydrogen-donating ability. The present findings showed that antioxidants were found in the culture supernatant of $B$. firmicutes had a noticeable DPPH free radical scavenging activity Figure 4. It was observed that the DPPH scavenging activity was increased in a dose dependent $(0-100 \mu \mathrm{g} / \mathrm{mL})$ manner. The greatest scavenging rate of antioxidants was $60 \%$. The results were less than that done by Liang et al. [38] who showed that scavenging rate of EPS isolated from $P$. mucilaginosus was $80 \%$, the $72 \%$ observed for Serratia ureilytica [39] and $77 \%$ for Paenibacillus sp. [40]. The halfmaximal effective concentration (EC50) of antioxidant 57 $\mu \mathrm{g} / \mathrm{mL}$, which was lower than that of the standard antioxidant ascorbic acid $(60 \mu \mathrm{g} / \mathrm{mL})$; antioxidants found in the culture supernatant of $B$. firmicutes were a potent and natural antioxidant that could be used as an alternative to synthetic antioxidants.

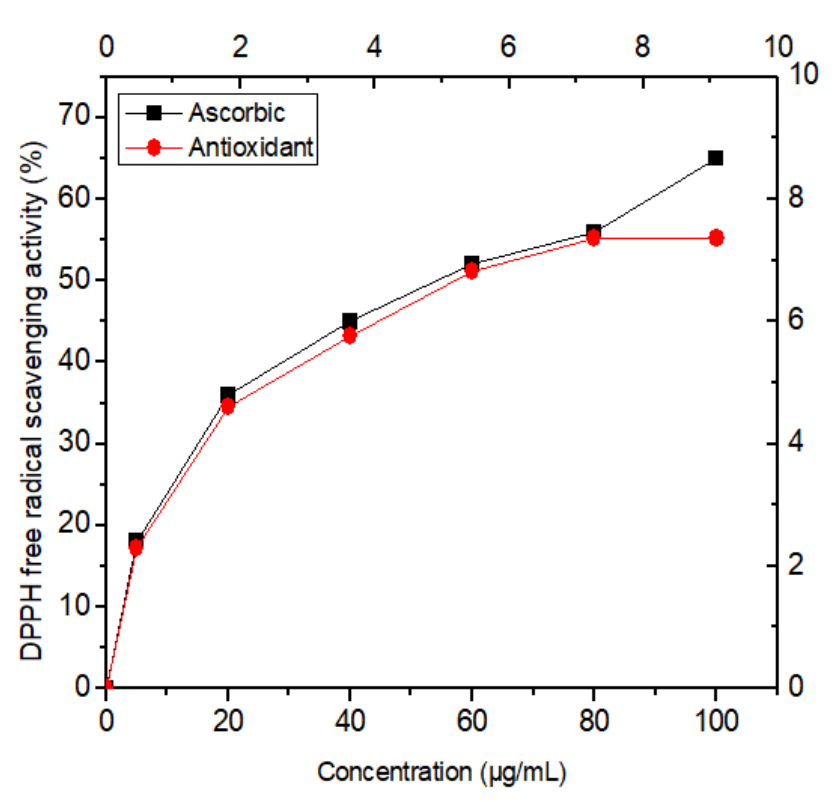

Figure 4. DPPH free radical scavenging ability B. firmicutes.
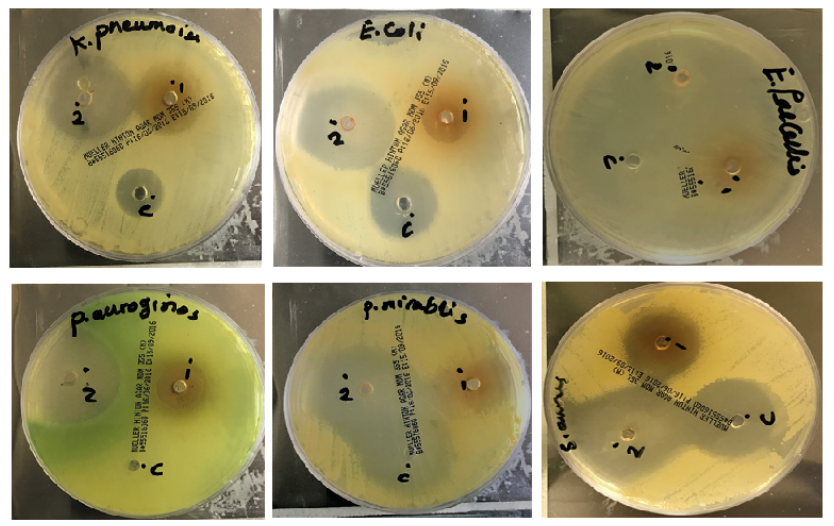

Figure 5. Inhibition zone produced by B. firmicutes. 1 methanol extract, 2 ethyl acetate extract, Augmentin antibiotic.

\section{Antimicrobial activity}

In the present study, the antibacterial activity of the extracted (methanolic, ethyl acetate) of $B$. firmicutes against pathogenic gram-negative and positive bacteria strains responsible for nosocomial infection such as $E$. coli, $K$. pneumonia, Acinotobacter baumannii, Ps. aeruginosa and Sta. aureus has been investigated by the using of agar-well diffusion method, based on the measure of the formed diameter of the inhibition zone. Both extracts exhibited a potent antibacterial activity against the tested bacteria, however the diameter of the inhibition zone depends mainly on the type of the used solvent for the extraction, the ethyl acetate is more effective than methanol against pathogenic bacteria.

As shown in Figure 5 and Table 3, highest antibacterial activity in ethyl acetate extract was observed against $E$. faecalis with a maximum diameter inhibition zone $25 \mathrm{~mm}$ while; the lowest activity was detected against $P$. aeruginosa diameter inhibition zone $14 \mathrm{~mm}$. While, the highest antibacterial activity in methanol extract was observed against $K$. pneumoniae and $E$. 
faecalis with a maximum diameter inhibition zone $15 \mathrm{~mm}$ and, the lowest activity was detected against $P$. aeruginosa diameter inhibition zone $10 \mathrm{~mm}$. On the other hand, the methanol extract did not exhibit antimicrobial activity against $E$. coli. Several lipopeptide biosurfactants obtained from Bacillus amyloliquefaciens M1 [41], Bacillus mojavensis A21 [42] and Bacillus methylotrophicus [43] showed strong antibacterial activity.

Table 3. Antimicrobial activity spectrum of B. firmicutes.

\begin{tabular}{lllll}
\hline Bacteria name & G & Control/m & Methanol & Ethyl acetate \\
\hline K. pneumoniae & G- & 10 & 15 & 17 \\
\hline E. coli & G- & 14 & 9 & 19 \\
\hline$P$. mirabilis & G- & 16 & 12 & 19 \\
\hline P. aeruginosa & G- & 0 & 10 & 14 \\
\hline E. faecalis & G+ & 14 & 15 & 25 \\
\hline S. aureus & G+ & 14 & 14 & 18 \\
\hline
\end{tabular}

\section{Minimum inhibitory concentration (MIC)}

In ethyl acetate extract $E$. faecalis, $E$. coli and $P$. mirabilis were the most sensitive bacteria with MIC values of 15,20 and 21 $\mathrm{mg} / \mathrm{mL}$ respectively while $P$. aeruginosa $30 \mathrm{mg} / \mathrm{ml}$. The methanol has less efficient than ethyl acetate extract. In case of ethyl acetate extract both $K$. pneumoniae and E. faecalis were the most sensitive bacteria with MIC values of 35 and 40 $\mathrm{mg} / \mathrm{ml}$ respectively. Many studies have underlined the importance of bacterial antibiotics in the food industry. Indeed, both nisin and pediocin PA-1 produced by lactic acid bacteria have been approved as food additives in many countries [44]. Our results are in agreement with the results of [45] that showed that new antibiotics and antioxidant S07-2 compound produced by Bacillus subtilis B38.

\section{Thin layer chromatography}

TLC for detection the antioxidant at different time: $50 \mathrm{ml}$ of culture medium were taken every day for $7 \mathrm{~d}$. The culture medium was centrifuged to separate the bacterial cells. The supernatants were evaporated to about $1.5 \mathrm{ml}$. $40 \mu \mathrm{l}$ for every day was applied on TLC (silica gel 60 F254). The developed TLC was visualized under UV lamp. UV-active organic compounds appeared as purple spots on TLC as seen Figure 6. As shown in Figure 6, in the front, first spot was found in all days even in the blank although it increases in the color in $4^{\text {th }}$ day. New spot detected from $1^{\text {st }}$ day, trace spot was detected in $1^{\text {st }}$ and $6^{\text {th }}$ day.

Detection of Antioxidant in methanol and ethyl acetate extracts: As shown in Figure 7 both ethyl acetate and methanol at two concentrations $(10-20 \mu \mathrm{L})$ were applied in TLC plate. The developed TLC was visualized under UV lamp. The front spot was found in ethyl acetate while methanol extract was found later from the front.

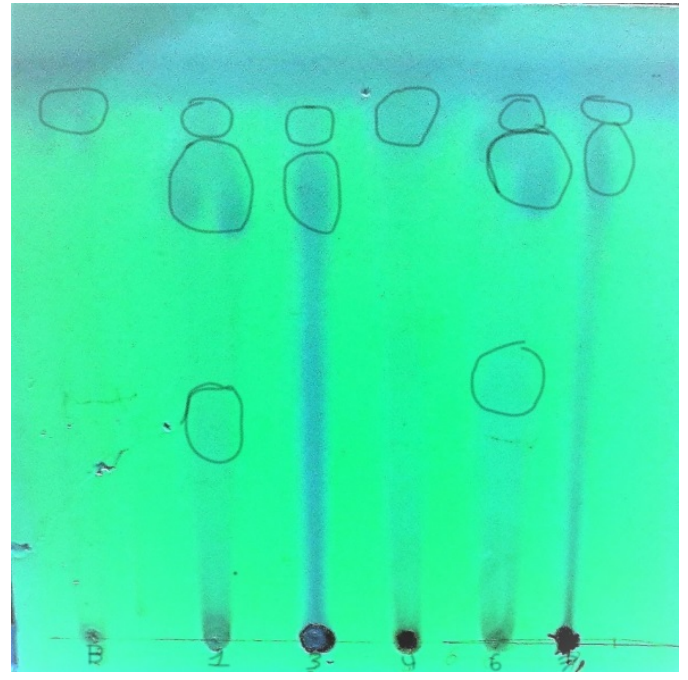

Figure 6. Thin-layer chromatography TLC analysis of antioxidant products for different fermentation time, $B$ : one spot; $1 d$ : 3 spots; 3 d: 2 spots; 4 d: 1 spot; 6 d: 3 spots; 7 d: 2 spots.

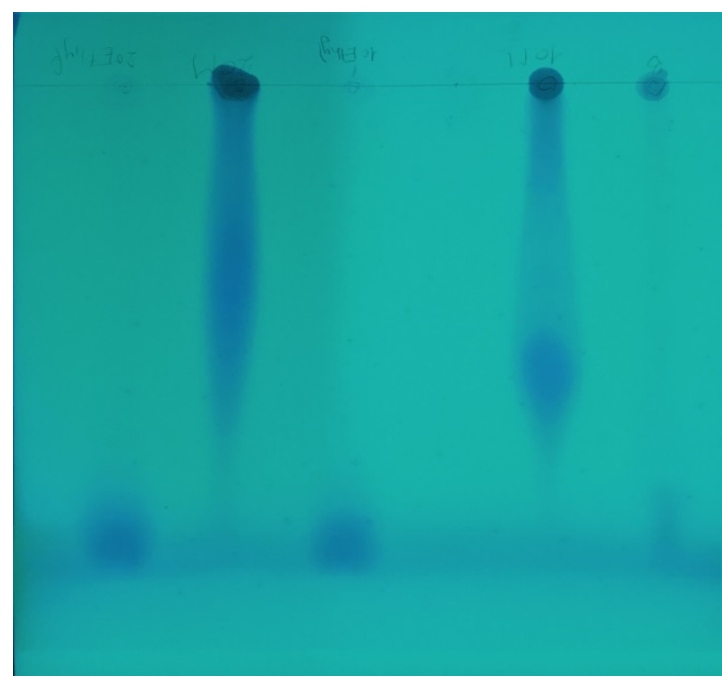

Figure 7. TLC of ethyl acetate and methanol extract of B. firmicutes supernatant.

\section{MS analysis}

The molecular mass of both extracts methanol and ethyl acetate compound were determined LCMS (Figures 8a and $8 \mathrm{~b})$. The mass spectrum confirmed the purity of methanol sample showed one major peak at $\mathrm{m} / \mathrm{z} 701$. Expansion of the chromatogram also showed minor species at $\mathrm{m} / \mathrm{z} 325$.

On the other hand, ethyl acetate sample showed one major peak at $\mathrm{m} / \mathrm{z} 304$ and minor one at $\mathrm{m} / \mathrm{z} 284$. The same results were observed by Hagelin et al. [46] who produced cyclic peptide antibiotics by $B$. subtilis species generally exhibit molecular masses $41000 \mathrm{Da}$, ranging from 1447.7 to $1519.8 \mathrm{Da}$ in the case of the maltacine complex, from 800 to $1500 \mathrm{Da}$ in the case of lipopeptides [47]. 


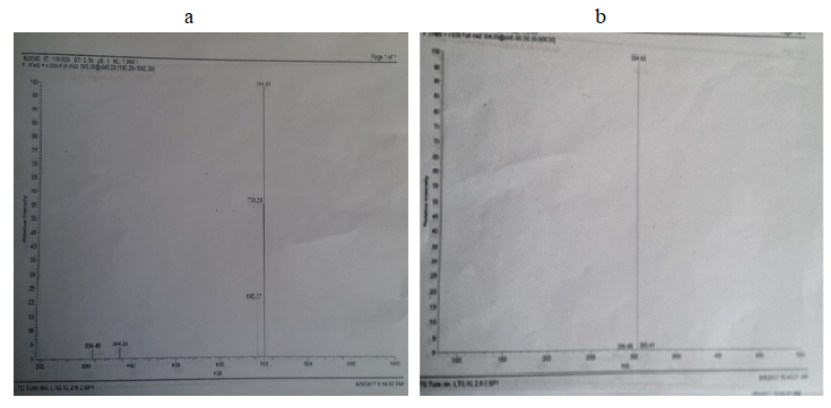

Figure 8. Mass spectrum profile of the methanol and ethyl acetate extracts. a) Methanol extract; b) Ethyl acetate.

\section{Conclusion}

Both ethyl acetate and methanol extract possess highest antibacterial activity against $E$. faecalis with a maximum diameter inhibition zone of $25 \mathrm{~mm}, 15 \mathrm{~mm}$ respectively while, the lowest activity was detected against $P$. aeruginosa with diameter inhibition zone $14 \mathrm{~mm}$ and $10 \mathrm{~mm}$ respectively.

\section{Acknowledgement}

This project was funded by the Deanship of Scientific Research (DSR) at King Abdulaziz University, Jeddah, under grant no. (646-130-1437). Authors, therefore, acknowledge with thanks DSR for technical and financial support.

\section{References}

1. Besbesa S, Bleckerb C, Deroanneb C, Drirac N-E, Attiaa H. Date seeds: chemical composition and characteristic profiles of the lipid fraction. Food Chem 2004; 84: 577-584.

2. Nigam PS. Production of bioactive secondary metabolites. Biotechnology for agro-industrial residues utilization. Springer, Netherlands 2009; 129-145.

3. Abou-Zeid AZ, Baeshin NA, Baghlaf AO. Utilization of date products in production of oxytetracycline by Streptomyces rimosus. J Chem Tech Biotechnol 1993; 58: 77-79.

4. Stein T. Bacillus subtilis antibiotics: structures, syntheses and specific functions. Mol Microbiol 2005; 56: 845-857.

5. May JJ, Wendrich TM, Marahiel MA. The dhb operon of Bacillus subtilis encodes the biosynthetic template for the catecholic siderophore 2, 3-dihydroxybenzoate-glycinethreonine trimeric ester bacillibactin. J Biol Chem 2001; 276: 7209-7217.

6. Moktan B, Saha J, Sarkar PK. Antioxidant activities of soybean as affected by Bacillus-fermentation to kinema. Food Res Int 2008; 41: 586-593.

7. Chew YL, Lim YY, Omar M, Khoo KS. Antioxidant activity of three edible seaweeds from two areas in South East Asia. LWT 2008; 41: 1067-1072.

8. Thitilertdecha N, Teerawutgulrag A, Rakariyatham N. Antioxidant and antibacterial activities of Nephelium lappaceum L. extracts. LWT-Food Sci Technol 2008; 41: 2029-2035.

9. Teow CC, Truong VD, McFeeters RF, Thompson RL, Pecota KV, Yencho GC. Antioxidant activities, phenolic and bcarotene contents of sweet potato genotypes with varying flesh colours. Food Chem 2007; 103: 829-838.

10. Erkan N, Ayranci G, Ayranci E. Antioxidant activities of rosemary (Rosmarinus officinalis L.) extract, black seed (Nigella sativa L.) essential oil, carnosic acid, rosmarinic acid and sesamol. Food Chem 2008; 110: 76-82.

11. Kumari PV, Shakila G, Selvi MT, Thilaka S. An impeccable studies on Bacillus simplex and it's in vitro antioxidant production, pre and post evaluation of antioxidant incorporation on food (Idly). Int $\mathrm{J}$ Pharma Biol Sci 2012; 2: 173-185.

12. Dey TB, Kuhad RC. Enhanced production and extraction of phenolic compounds from wheat by solid-state fermentation with Rhizopus oryzae RCK2012. Biotechnol Rep 2014; 4: 120-127.

13. Matsuo M. Morphological and physicochemical properties and composition of "Okara" fermented with Rhizopus oligosporus. J Japan Soc Nutr Food Sci 1989; 42: 173-178.

14. Lertcanawanichakul $\mathrm{M}$, Pondet $\mathrm{K}$, Kwantep J. In vitro antimicrobial and antioxidant activities of bioactive compounds (secondary metabolites) extracted from Streptomyces lydicus A2. J Appl Pharm Sci 2015; 5: 17-21.

15. Kiruthika $\mathrm{P}$, Nisshanthini S, Angayarkanni J. In vitro Antimicrobial and antioxidant profile of Streptomyces Sp. isolated from Coromandel Coast region, India. Int $\mathrm{J}$ Pharma BioSci 2013; 4: 127-136.

16. Mueller J, Hinton J. A protein-free medium for primary isolation of the gonococcus and meningococcus. Exp Biol Med 1941; 48: 330-333.

17. Rai SK, Roy JK, Mukherjee AK. Characterization of a detergent-stable alkaline protease from a novel thermophilic strain Paenibacillus tezpurensis sp. Appl Microbiol Biotechnol 2010; 85: 1437-1450.

18. Tamura A, Shimizu YK, Tanaka T, Kuroda K, Kuroda Y, Takahashi K. Persistent infection of hepatitis $\mathrm{E}$ virus transmitted by blood transfusion in a patient with T-cell lymphoma. Hepatol Res 2007; 37: 113-120.

19. Hajlaoui H, Trabelsi N, Noumi E, Snoussi M, Fallah H, Ksouri R, Bakhrouf A. Biological activities of the essential oils and methanol extract of tow cultivated mint species (Mentha longifolia and Mentha pulegium) used in the Tunisian folkloric medicine. World J Microbiol Biotechnol 2009; 25: 2227-2238.

20. Smânia A, Monache FD, Smânia EFA, Cuneo RS. Antibacterial activity of steroidal compounds isolated from Ganoderma applanatum (Pers.) Pat. (Aphyllophoromycetideae) Fruit body. Int J Med Mushrooms 1999; 1: 325-330. 
21. CLSI. Methods for dilution antimicrobial susceptibility tests for bacteria that grow aerobically; approved standard (9th Edition). CLSI Document 2012; M07-A9.

22. A.O.A.C. Official methods of analysis. Association of Official Analytical Chemist, Washington DC 1999; 69-70.

23. Abbasi MA, Saleem H, Rehman A-UR, Riaz T, Ajaib M. Determination of antioxidant activity and phytoconstituent screening of euphorbia heterophylla Linn. Brit J Pharma Res 2013; 3: 202-216.

24. Sun B, Ricardo-da-Silva JM, Spranger I. Critical factors of vanillin assay for Catechins and Proanthocyanidins. J Agricultural Food Chem 1998; 46: 4267-4274.

25. Prieto-Simón $B$, Cortina $M$, Campàs M, Calas-Blanchard C. Electrochemical biosensors as a tool for antioxidant capacity assessment. Sens Actuators B Chem 2008; 129: 459-466.

26. El Hajaji H, Lachkar N, Alaoui K, Cherrah Y, Farah A, Ennabili A, El Bali B, Lachkar M. Antioxidant properties and total phenolic content of three varieties of carob tree leaves from Morocco. Rec Nat Prod 2010; 4: 193-204.

27. Leong LP, Shui G. An investigation of antioxidant capacity of fruits in Singapore markets. Food Chem 2002; 76: 69-75.

28. Kahkonen MP, Hopia AI, Vuorela HJ. Antioxidant activity of plant extracts containing phenolic compounds. J Agric Food Chem 1999; 47: 3954-3962.

29. FAOSTAT. Statistical databases. Food and Agriculture Organisation of the United Nations 2013.

30. Attalla AM, Harraz FM. Chemical composition of the pits of selected date palm cultivars grown in the Qassim region. Gulf J Sci Res 1996; 14: 629-639.

31. Hamada JS, Hashim IB, Sharif FA. Preliminary analysis and potential uses of date pits in foods. Food Chem 2002; 76: $135-137$.

32. Al-Farsi M, Alasalvar C, Al-Abid M, Al-Shoaily K, AlAmry M, Al-Rawahy F. Compositional and functional characteristics of dates, syrups, and their by-products. Food Chem 2007; 104: 943-947.

33. Deschamps AM, Lebeault J. Production of Gallic acid from Tara tannin by bacterial strains. Biotechnol Lett 1984; 6: 237-242.

34. Janardhan A, Kumar AP, Viswanath B, Saigopal DVR, Narasimha G. Production of bioactive compounds by Actinomycetes and their antioxidant properties. Biotechnol Res Int 1984; 1-8.

35. Machu L. Phenolic content and antioxidant capacity in algal food products. Algal Food Products 2015; 20: 1118-1133.

36. Tebbal A, Hadjazi D, Benine M.L, Chama Z, Arab K, Benmahdi L, Benali M, Abbouni B. Determination of the total phenolic content and antibacterial activity of isolated Cyanobacteria from Algerian freshwater against some nosocomial pathogens bacteria. Der Pharmacia Lettre 2017; 9: 73-83.

37. Martins RF, Ramos MF, Herfindal L, Sousa JA, Skaerven $\mathrm{K}$, Vasconcelos VM. Antimicrobial and cytotoxic assessment of marine cyanobacteriaSynechocystis and Synechococcus. Mar Drugs 2008; 6: $1-11$.

38. Liang TW, Tseng SC, Wang SL. Production and characterization of antioxidant properties of exopolysaccharide(s) from Peanibacillus mucilaginosus TKU032. Mar Drugs 2016; 14: 40-51.

39. Wang CL, Huang TH, Liang TW, Fang CY, Wang SL. Production and characterization of exopolysaccharides and antioxidant from Paenibacillus sp. TKU023. N Biotechnol 2011; 28: 559-565.

40. Wang SL, Liu KC, Liang TW, Kuo YH, Wang CY. In vitro antioxidant activity of liquor and semi-purified fractions from squid pen biowaste by Serratia ureilytica TKU013. Food Chem 2010; 119: 1380-1385.

41. $\mathrm{Xu} \mathrm{HM,} \mathrm{Rong} \mathrm{YJ,} \mathrm{Zhao} \mathrm{MX,} \mathrm{Song} \mathrm{B,} \mathrm{Chi} \mathrm{ZM.}$ Antibacterial activity of the lipopetides produced by Bacillus amyloliquefaciens M1 against multidrug resistant Vibrio spp. isolated from diseased marine animals. Appl Microbiol Biotechnol 2014; 98: 127-136.

42. Ben AH, Hmidet N, Béchet M, Chollet M, Chataigna G, Leclère $\mathrm{V}$. Identification and biochemical characteristics of lipopeptides from Bacillus mojavensis A21. Process Biochem 2014; 49: 1699-1707.

43. Jemil N, Ben AH, Manresan A, Nasri M, Hmidet N. Antioxidant properties, antimicrobial and anti-adhesive activities of DCS1lipopeptides from Bacillus methylotrophicus DCS1. BMC Microbiol 2017; 17: 144-155.

44. Cotter PD, Hill C, Ross RP. Bacteriocins: developing innate immunity for food. Nat Rev Microbiol 2005; 3: 777-788.

45. Tabbene O, Karkouch I, Elkahoui S, Cosette P, Mangoni M-L, Jouenne T, Limam F. A new antibacterial and antioxidant S07-2 compound produced by Bacillus subtilis B38. FEMS Microbiol Lett 2010; 303: 176-182.

46. Hagelin G, Oulie I, Raknes A, Undheim K, Clausen OG. Preparative high-performance liquid chromatographic separation and analysis of the maltacine complex-a family of cyclic peptide antibiotics from Bacillus subtilis. J Chromatogr B 2004; 811: 243-251.

47. Price NPJ, Rooney AP, Swezey JL, Perry E, Cohan FM. Mass spectrometric analysis of lipopeptides from Bacillus strains isolated from diverse geographical locations. FEMS Microbiol Lett 2007; 271: 83-89.

\section{*Correspondence to}

Youssri M Ahmed

Department of Biochemistry

Faculty of Science

King Abdulaziz University

Saudi Arabia 